\title{
Demographic, anthropometric and laboratory characteristics in obese children
}

\author{
Cristian Dan Marginean', Nicoleta Tomsa², Bianca Aron², Daniela Ciobanu², Lorena Elena Melit ${ }^{1,2}$ \\ 1“G.E. Palade” University of Medicine, Pharmacy, Sciences and Tehnology, Tg. Mures, Romania \\ ${ }^{2}$ Pediatrics Clinic, Emergency Clinical County Hospital, Tg. Mures, Romania
}

\begin{abstract}
Introduction. The incidence of obesity reached alarming rated in pediatric population resulting in a global public health problem. The aim of our study consists of the assessment of anthropometric and laboratory parameters in obese children.

Material and method. We performed a retrospective observational study on 155 children, with the age between 5 and 17 years admitted in the Pediatrics Clinic $1 \mathrm{Tg}$. Mures, who were divided according to BMI in: group I - 65 children with a BMI over percentile (P) 95; group II - 90 children with normal BMI, between P5 and P85.

Results. The mean age of the obese children was significantly higher as compared to normal weight ones $(p=0.0007)$. Parental weight was significantly higher in obese children in comparison to normal weight ones $(p=0.0074, p=0.0062)$. Anthropometric parameters had significantly higher values in group I as compared to group II $(p<0.0001)$. Most of CBC parameters had significantly higher levels in children with obesity, except for hemoglobin. T Chol, LDL and TG levels were also significantly higher in obese children as compared to those from control group ( $p=0.0229 / p=0.0049 / p=0.0058)$, while HDL was significantly higher in normal weight children $(p=0.0419)$. AST and ALT presented significantly elevated levels in case of group I $(p=0.0045 / p<0.0001)$.

Conclusions. The incidence of obesity in small ages is increasing. Anthropometric and laboratory parameters might represent accurate indicators of obesity in children.
\end{abstract}

Keywords: obese children, anthropometric parameters, laboratory parameters

\section{INTRODUCTION}

Obesity has become during the last decades a global public health problem independently of the age. The evolution of this nutritional disorder is hindered by multiple short and long-term complications. Even though most of the studies published in the literature involve adult populations, the assessment of obesity in pediatric ages is particularly important since it is well-documented that an obese child is a future obese adult. Moreover, the incidence of obesity in pediatric patients has reached alarming rates. Thus, the World Health Organization stated that the prevalence of obesity nearly tripled since 1975 (1). In 2016, 41 million children below the age of 5 years were identified as overweight or obese (1). This prevalence increases with age since it was noticed that above the age of 5 years, over 340 million children and adolescent suffer from overweight or obesity (1).

The etiology of obesity is multifactorial involving both genetic and environmental factors (2). Genetic predisposition expressed by different genes with increased risk for developing obesity in mandatory in the determinism of this nutritional disorder (2). Nevertheless, the decisive role for developing the phenotype is owned by environmental factors, also known as 'obesogenic' factors being proved that, except for genetic syndromes morbid obesity, in the absence of these factors, individuals with genetic predisposition will not develop this disorder. The multisystemic complications associated with obesity include type 2 diabetes mellitus, dyslipidemia, metabolic syndrome, non-alcoholic steatohepatitis, hepatic fibrosis or cirrhosis, and least but not last, a wide spectrum of car- 
diovascular pathologies (3). Contemporary studies suggested that these complications might be a consequence of low-grade systemic inflammation identified in obese patients regardless of the age $(4,5)$.

Taking into account all the above mentioned facts, the assessment of an obese patient might represent a multidisciplinary challenge for an early diagnosis of potential complications, and ever for their prevention. Contemporary medicine focuses on the approach of non-invasive or minimally invasive methods in all areas, especially in pediatric ages where child's and parents' compliance are even more reduces when compared to adult patients. Thus, the assessment of weight (W), height $(\mathrm{H})$, body mass index (BMI), abdominal circumference (AC), hip circumference $(\mathrm{HC})$, midupper arm circumference (MUAC) and tricipital skinfold thickness (TST) are among the most used indicators in obese patients. The assessment of inflammatory status associated to obesity by analyzing the complete cellular blood count (CBC), acute phase reactants or different adipokines might also be extremely useful in children diagnosed with obesity $(6,7)$. Obesity-associated hepatic conditions are another key point in the assessment of pediatric patients with obesity. Despite the fact that hepatic biopsy remains the gold-standard in the diagnosis of hepatic diseases, new ultrasonography-based techniques such as liver elastography might be useful in predicting hepatic impairment in both obese adult and pediatric populations (8-10).

\section{AIM}

The aim of our study consists in the assessment of demographic, anthropometric and laboratory parameters in obese children.

\section{MATERIAL AND METHOD}

Our study was a retrospective observational one which included 155 children with the age between 5 and 17 years admitted in the Pediatrics Clinic I Tg. Mures since May 2017 until October 2019. Depending on the BMI, the children were divided into two groups as it follows: group I, study group, which included 65 children with a BMI above percentile $(\mathrm{P})$ 95 - obese children; and groups II, control group, 90 children with a BMI between $\mathrm{P}_{5}$ and $\mathrm{P}_{85}$ - normal weight children The inclusion criterion consisted in the age between 5 and 18 years, whereas the exclusion criteria were: secondary obesity, associated chronic disorders, infectious diseases suggested by symptoms or laboratory tests, patients with incomplete data or those whose care-givers refused to sign the informed consent prior to the inclusion in the study. All patients included in the study underwent anamnesis, clinical exam with the assessment of anthropometric parameters (W, H, AC, MUAC, HC, TST, and laboratory parameters $(\mathrm{CBC}$, erythrocyte sedimentation rate $-\mathrm{ESR}$, total cholesterol - T Chol, HDL-cholesterol - HDL, LDL-cholesterol - LDL, triglycerides - TG, aspartate aminotransferase - AST, alanine aminotransferase ALT, glycaemia - GLI, total proteins - T Prot). Regarding anthropometric parameters, all patients were assessed by a single trained person. Thus, W was measured with a scale with an error of $\pm 10 \mathrm{~g}$, for $\mathrm{H}$ we used a daily calibrated pedometer with a standard error of $0.1 \mathrm{~cm}$, MUAC was measured at the midpoint between shoulder and elbow, TST mas measured at the same point on the posterior area of the arm with a caliper, AC was assessed at the midpoint between costal rip margin and anterior ilium spine, and $\mathrm{HC}$ was assessed on the buttocks.

The statistical analysis comprised descriptive statistics elements (mean, median, standard deviation) and elements of inferential statistics. Shapiro-Wilk test was applied for assessing the distribution of analyzed series of data. In order to compare the means we used t-Student test for unpaired data, t-Student test with Welch correction and Mann-Whitney test for median comparison. The significance threshold for $p$ value was 0.05 . The statistical analysis was performed using GraphPad Prism trial variant.

All parents/care-givers signed the informed consent for the children inclusion in the study, The study was performed according to the principles of the Helsinki Declaration and it was approved by the Ethics Committee of the „George Emil Palade“ University of Medicine, Pharmacy, Sciences and TechnologyTg. Mures no 35/07.04.2017.

\section{RESULTS}

Our study performed on 155 children comprised 65 obese children and 90 normal weight ones. The mean age of obese children included in the study was significantly smaller than of normal weight ones, i.e. $10.25 \pm 3.28$ versus $12.18 \pm 3.48$ years $(p=0.0007)$. The children included in the study group has a significantly higher birth weight as compared to those from control group, but without statistical significance ( $p=0.1828)$. Regarding the height, children with normal weight included in our study were significantly taller as compared to the obese ones $(152.40 \pm 15.83$ versus $145.40 \pm 18.58 \mathrm{~cm}, \mathrm{p}=0.0111)$. We also assessed parental weight, and we noticed that both mother's and father's weight are significantly higher 
TABLE 1. The demographic characteristics of the two groups

\begin{tabular}{|c|c|c|c|c|c|}
\hline \multirow[t]{2}{*}{ Variables } & \multicolumn{2}{|c|}{ Children with obesity (Study group) } & \multicolumn{2}{|c|}{ Normal weight children (Control group) } & \multirow[t]{2}{*}{ p } \\
\hline & $\begin{array}{l}\text { Mean } \pm S D \\
\text { (Median) }\end{array}$ & $\begin{array}{c}\text { Range } \\
{[\text { min-max] }}\end{array}$ & $\begin{array}{l}\text { Mean } \pm \text { SD } \\
\text { (Median) }\end{array}$ & $\begin{array}{c}\text { Range } \\
{[\text { min-max] }}\end{array}$ & \\
\hline Age (years) & $10.25 \pm 3.28(10)$ & {$[5.00-17.00]$} & $12.18 \pm 3.48(13)$ & [5.00-17.00] & $* 0.0007$ \\
\hline Birth weight (kg) & $3.31 \pm 0.54(3.3)$ & [2.095-4.880] & $3.28 \pm 1.052(3.2)$ & [2.060-3.670] & $* 0.1828$ \\
\hline Actual weight (kg) & $59.35 \pm 22.54(58.3)$ & {$[22.60-109.00]$} & $45.08 \pm 14.05(45.95)$ & [18.30-76.50] & $<0.0001$ \\
\hline Height (cm) & $145.40 \pm 18.58(145)$ & [106.00-188.00] & $152.40 \pm 15.83(155)$ & [116.00-183.00] & $* 0.0111$ \\
\hline Mother's weight (kg) & $75.56 \pm 14.18(75)$ & {$[47.00-112.00]$} & $69.21 \pm 13.60(66)$ & {$[45.00-105.00]$} & $* 0.0074$ \\
\hline Father's weight (kg) & $92.92 \pm 16.05(91)$ & {$[65.00-135.00]$} & $86.16 \pm 17.55(85)$ & {$[58.00-170.00]$} & $* 0.0062$ \\
\hline
\end{tabular}

in case of obese children as compared to the normal weight ones $(\mathrm{p}=0.0074 / \mathrm{p}=0.0062)$.

All demographic data of the patients included in our study are mentioned in Table 1.

The anthropometric parameters assessed in both groups included in our study comprised BMI, MUAC, TST, AC and HC. Thus, all these parameters presents significantly higher values in obese children as compared to normal weight ones: BMI $26.87 \pm 4.833 \mathrm{~kg} / \mathrm{m}^{2}$ versus $18.9 \pm 2.92 \mathrm{~kg} / \mathrm{m}^{2}(\mathrm{p}<0.0001) ;$ MUAC $29.27 \pm 4.546 \mathrm{~cm}$ versus $23.59 \pm 3.798 \mathrm{~cm}(\mathrm{p}<0.0001)$, TST $19.34 \pm 6.745 \mathrm{~mm}$ versus $23.59 \pm 3.798 \mathrm{~mm}(\mathrm{p}<$ $0.0001), \mathrm{HC} 89.2 \pm 14.97 \mathrm{~cm}$ versus $74.16 \pm 12.4 \mathrm{~cm}(\mathrm{p}$ $<0.0001)$, AC $89.29 \pm 15.05 \mathrm{~cm}$ versus $67.82 \pm 9.118$ $\mathrm{cm}(\mathrm{p}<0.0001)$ (Table 2).
Regarding the laboratory tests, we assessed both $\mathrm{CBC}$ and multiple biochemical parameters in the two groups included in our study (Table 3). Most of the CBC parameters were significantly higher in obese children as compared to normal weight ones, except for hemoglobin, which was higher in control group, but without statistical significance. ESR as an acute phase reactant was also significantly higher in obese children as compared to normal weight ones $(\mathrm{p}=$ 0.0344). Among the lipid profile parameters, T Chol, LDL and TG were significantly higher in children included in the study group in comparison to those from control group $(\mathrm{p}=0.0229 / \mathrm{p}=0.0049 / \mathrm{p}=0.0058)$. Contrariwise, HDL was significantly higher in children with normal weight when compared to obese

TABLE 2. The anthropometric parameters of the two groups

\begin{tabular}{|c|c|c|c|c|c|}
\hline \multirow[b]{2}{*}{ Variables } & \multicolumn{2}{|c|}{ Study group } & \multicolumn{2}{|c|}{ Control group } & \multirow[b]{2}{*}{ p } \\
\hline & $\begin{array}{l}\text { Mean } \pm S D \\
\text { (Median) }\end{array}$ & $\begin{array}{c}\text { Range } \\
\text { [min-max] }\end{array}$ & $\begin{array}{l}\text { Mean } \pm S D \\
\text { (Median) }\end{array}$ & $\begin{array}{c}\text { Range } \\
\text { [min-max] }\end{array}$ & \\
\hline BMI $\left(\mathrm{kg} / \mathrm{m}^{2}\right)$ & $26.87 \pm 4.833(26.1)$ & [19.1-40.9] & $18.9 \pm 2.92(18.6)$ & {$[13.5-27.4]$} & $<0.0001$ \\
\hline $\operatorname{MUAC}(\mathrm{cm})$ & $29.27 \pm 4.546(29)$ & [20-40] & $23.59 \pm 3.798(24)$ & [15-32] & $<0.0001$ \\
\hline TSF $(\mathrm{mm})$ & $19.34 \pm 6.745(18.1)$ & [5-37.5] & $12.96 \pm 4.741(12.71)$ & [4.56-31.87] & $*<0.0001$ \\
\hline $\mathrm{HC}(\mathrm{cm})$ & $89.2 \pm 14.97(88)$ & [62-127] & $74.16 \pm 12.4(75)$ & [14.36-103] & $*<0.0001$ \\
\hline$A C(\mathrm{~cm})$ & $89.29 \pm 15.05(89)$ & [59-134] & $67.82 \pm 9.118(68)$ & {$[49-86]$} & $<0.0001$ \\
\hline
\end{tabular}

TABLE 3. Laboratory parameters of the two groups

\begin{tabular}{|c|c|c|c|c|c|}
\hline \multirow[b]{2}{*}{ Variables } & \multicolumn{2}{|c|}{ Study group } & \multicolumn{2}{|c|}{ Control group } & \multirow[b]{2}{*}{$\mathbf{p}$} \\
\hline & $\begin{array}{l}\text { Mean } \pm S D \\
\text { (Median) }\end{array}$ & $\begin{array}{c}\text { Range } \\
\text { [min-max] }\end{array}$ & $\begin{array}{l}\text { Mean } \pm S D \\
\text { (Median) }\end{array}$ & $\begin{array}{c}\text { Range } \\
\text { [min-max] }\end{array}$ & \\
\hline Erythrocytes $\left(10^{3} / \mu \mathrm{l}\right)$ & $4.969 \pm 0.3864(4.98)$ & [3.66-5.91] & $4.821 \pm 0.3666(4.75)$ & [4.191-6.13] & $* 0.0010$ \\
\hline Hemoglobin (g/dl) & $13.38 \pm 1.289(13.6)$ & [8.3-15.8] & $13.53 \pm 1.1(13.3)$ & [10.6-17.1] & $* 0.7841$ \\
\hline Leukocytes $\left(10^{3} / \mu \mathrm{l}\right)$ & $8178 \pm 2915(7470)$ & [1222-22720] & $7138 \pm 1904(6640)$ & [4180-12190] & $* 0.0045$ \\
\hline Neutrophils $\left(10^{3} / \mu \mathrm{l}\right)$ & $4483 \pm 2284(3790)$ & [1950-14180] & $3850 \pm 1803(3450)$ & [1170-10050] & $* 0.0464$ \\
\hline Lymphocytes $\left(10^{3} / \mu \mathrm{l}\right)$ & $2897 \pm 1014(2680)$ & {$[1060-7820]$} & $2373 \pm 718(2300)$ & {$[880-4690]$} & $* 0.0001$ \\
\hline Platelets $\left(10^{3} / \mu \mathrm{l}\right)$ & $337.3 \pm 91.48(321.5)$ & [99-553] & $290.6 \pm 66.46(284)$ & [157-485] & $* 0.0008$ \\
\hline ESR $(\mathrm{mmHg})$ & $13.14 \pm 8.782(12)$ & {$[2-39]$} & $10.92 \pm 8.822(6)$ & {$[2-31]$} & $* 0.0344$ \\
\hline T Chol (mg/dl) & $159.6 \pm 27.32(156.2)$ & [106.7-233] & $149.8 \pm 29.6(146.3)$ & {$[50.76-220.5]$} & $* 0.0229$ \\
\hline HDL (mg/dl) & $44.44 \pm 11.31(43.26)$ & {$[22.86-76.87]$} & $48.97 \pm 12.43(47.15)$ & {$[26.77-88.60]$} & $* 0.0419$ \\
\hline LDL (mg/dl) & $91.74 \pm 25.07(91.02)$ & [46-169] & $80.80 \pm 22.25(77.27)$ & [41-135.9] & $* 0.0049$ \\
\hline TG (mg/dl) & $105.8 \pm 57.01(90.8)$ & [39.4-358] & $85.22 \pm 42.39$ (77.75) & {$[26-292.8]$} & $* 0.0058$ \\
\hline AST (u/l) & $28.4 \pm 25.5(23.9)$ & [12-214.9] & $22.44 \pm 12(20.4)$ & [11.1-109.2] & $* 0.0045$ \\
\hline ALT (u/l) & $28.43 \pm 46.65(18.2)$ & {$[8.4-373.4]$} & $14.54 \pm 9.671(12.1)$ & {$[6.6-74.5]$} & $*<0.0001$ \\
\hline T Prot (mg/dl) & $7.559 \pm 0.4866(7.52)$ & [5.84-8.69] & $7.497 \pm 0.4314$ (7.49) & {$[6.34-8.47]$} & 0.4050 \\
\hline Gli (mg/dl) & $86.6 \pm 10.17(85.6)$ & {$[58.5-114.1]$} & $85.63 \pm 9.143(84.4)$ & [49.4-111.5] & $* 0.6597$ \\
\hline
\end{tabular}


ones $(\mathrm{p}=0.0419)$. The assessment of liver function pointed our higher values of both transaminases, AST and ALT in children diagnosed with obesity as compared to the normal weight ones $(p=0.0045 /$ $p<0.0001)$. We noticed higher values of $T$ Prot and Gli in obese children in comparison to those with normal weight, but without statistical significance $(\mathrm{p}=$ $0.4050 / \mathrm{p}=0.6597)$.

\section{DISCUSSIONS}

Childhood obesity reached alarming rates worldwide resulting in an increase of associated complications. A study performed on children from Romania proved that $11.6 \%$ of those below the age of 8 years are diagnosed with obesity, whereas $26.8 \%$ are overweight (11). Similarly, the mean age of the obese children included in our study was significantly smaller as compared to normal weight children. Multiple studies proved that birth weight is influenced by maternal excessive gestational weight, being significantly higher in newborns from mothers with excessive gestational weight gain as compared to those whose mothers gained a normal weight during pregnancy (12-15). Moreover, a study performed on Romanian obese children pointed out a higher birth weight in obese children as compared to the normal weight ones suggesting that increased birth weight might lead in an excessive weight gain during childhood (5). Our findings sustain these studies since our study group also present a higher birth weight as compared to control group. Parental weight might influence offspring's weight regarding both genetic factors and dietary habits or sedentary lifestyle (16). Similarly, our study proved that parent's weight was higher in case of obese children as compared to normal weight ones.

Anthropometric parameters are important as a part of the non-invasive assessment of obese children, being correlated with different indicators of visceral fat. A study similar to ours, which included 121 obese children and 143 normal weight ones pointed out significantly higher values of MUAC, TST, AC and HC in case of children with obesity than of those included in control group (17). Similarly, our results showed higher values of anthropometric parameters in obese children as compared to normal weight ones.

$\mathrm{CBC}$ parameters are used in diagnosing low-grade systemic inflammation associate to obesity (5) given the wide-spectrum of complication that result from this systemic inflammation. According to a study performed on 223 patients, an increase in BMI is associated with a higher count of leukocytes, lymphocytes, neutrophils and platelets (18). Moreover, it was hypothesized that inflammatory status is better reflected by neutrophil count, while the nutritional and general ones are better expressed by lymphocyte count (19), and the degree of obesity is directly related to the neutrophil count (20). Acute phase reactants such as Creactive protein and ESR are other parameters that were directly correlated with the systemic inflammatory status identified in obese patients $(21,22)$. Other studies proved that an increase in platelets count might represent an important risk factor in obese patients (23). Regarding our study, the findings are similar to those mentioned above since we also noticed a significantly higher number of leukocytes, neutrophils, lymphocytes and platelets in obese children as compared to those from control group. Moreover, obese children presented higher values of ESR in comparison to the normal weight ones.

Lipid profile own a particular importance in the assessment of pediatric patients with obesity since this disorder is associated with early atherosclerosis, a major cardiovascular risk factor that persists into adulthood (24). Thus, it was proved that increased levels of LDL along with decreased ones of HDL contribute to the formation of atherosclerotic plaques (25). Moreover, the association between hypertriglyceridemia and a decrease in HDL might lead to insulin resistance (26). Assessing these cardiovascular and metabolic risk factors in our study, we noticed that despite the small age of the studied population, the levels of T Chol, LDL and TG were significantly higher in patients diagnosed with obesity as compared to those with a normal nutritional status. Moreover, significantly lower levels of HDL were identified among children from the study group as compared to those included in control group.

It is well-known that obese patients suffer from different degrees of liver impairment, from simple steatosis to advanced fibrosis, and even cirrhosis. Non-alcoholic fatty liver disease has become during the last decades the most common form of chronic hepatic condition, with a prevalence of $5-17 \%$ in Western countries (27). Thus, the routine assessment off transaminases, bilirubin, fasting glucose and lipid profile parameters are useful in patients with metabolic syndrome for the prediction of hepatic impairment (28). Similarly, the obese children included in our study had higher values of transaminases and glycaemia as compared to normal weight ones.

The limitations of our study consist of the relatively small sample, the lack of evaluation of genetic factors and dietary habits in the determinism of obesity, but also the fact that the studied population comes from a single area of our country. Nevertheless, our study might be considered a pilot one being among 
the few that assessed both anthropometric and laboratory parameters in children.

\section{CONCLUSIONS}

Obesity in pediatric ages might represent either a risk factor for long-term complications, or the ideal moment for their prevention. Anthropometric parameters are correlated with obesity in children and might represent useful tools for the diagnosis of this disor-

\section{REFERENCES}

1. WHO | Overweight and obesity [Internet]. [cited 2019 Jan 25]. Available from: https://www.who.int/gho/ncd/risk_factors/overweight/ en/.

2. Mărginean $C O$, Mărginean $C$, Meliţ LE. New Insights Regarding Genetic Aspects of Childhood Obesity: A Minireview. Front Pediatr. 2018:6:271.

3. Tilg $\mathrm{H}$, Moschen AR. Adipocytokines: mediators linking adipose tissue, inflammation and immunity. Nat Rev Immunol. 2006 Oct;6 (10):772-83.

4. Ferrante AW. Obesity-induced inflammation: A metabolic dialogue in the language of inflammation. J Intern Med. 2007 Oct;262 (4):408-14.

5. Mărginean C, Meliț L, Ghiga D, Mărginean M. Early inflammatory status related to pediatric obesity (STROBE compliant article). Front Pediatr. 2019;7.

6. Aydin M, Yilmaz A, Donma MM, Tulubas F, Demirkol M, Erdogan M et al. Neutrophil/lymphocyte ratio in obese adolescents. North Clin Istanb. 2015;2 (2):87-91.

7. Mărginean CO, Meliţ LE, Huțanu A, Ghiga DV, Săsăran MO. The adipokines and inflammatory status in the era of pediatric obesity. Cytokine. 2020 Feb;126:154925.

8. Garcovich M, Veraldi S, Di Stasio E, Zocco MA, Monti L, Tomà P, et al. Liver Stiffness in Pediatric Patients with Fatty Liver Disease: Diagnostic Accuracy and Reproducibility of Shear-Wave Elastography. Radiology. 2017:283 (3):820-7.

9. Hudert CA, Tzschätzsch H, Guo J, Rudolph B, Bläker H, Loddenkemper $\mathrm{C}$ et al. US Time-Harmonic Elastography: Detection of Liver Fibrosis in Adolescents with Extreme Obesity with Nonalcoholic Fatty Liver Disease. Radiology. 2018;288 (1):99-106.

10. Mărginean CO, Meliţ LE, Ghiga DV, Săsăran MO. The assessment of liver fibrosis in children with obesity on two methods: Transient and two dimensional shear wave elastography. Sci Rep. 2019 Dec 24;9 (1):19800.

11. Chirita-Emandi A, Barbu CG, Cinteza EE, Chesaru BI, Gafencu M, Mocanu $V$ et al. Overweight and Underweight Prevalence Trends in Children from Romania - Pooled Analysis of Cross-Sectional Studies between 2006 and 2015. Obes Facts. 2016;9 (3):206-20.

12. Marginean C, Marginean C, lancu M, Melit L, Tripon F, Banescu C. MC4R and ENPP1 gene polymorphisms and their implication in maternal and neonatal risk for obesity. Scientific Reports. 2019;9 (10858):1-9.

13. Mărginean $C$, Mărginean $C O$, lancu M, Meliţ LE, Tripon F, Bănescu C. The FTO rs9939609 and LEPR rs1137101 mothers-newborns gene polymorphisms and maternal fat mass index effects on anthropometric characteristics in newborns: A cross-sectional study on mothers-newborns gene polymorphisms-The FTO-LEPR Study (STROBE-compliant article). Medicine (Baltimore). 2016 Dec;95 (49):e5551.

14. Mărginean $C$, Mărginean $C O$, lancu $M$, Szabo $B$, Cucerea $M$, Melit LE et al. The role of TGF- $\beta 1869 \mathrm{~T}>\mathrm{C}$ and PPAR $\gamma 234 \mathrm{C}>\mathrm{G}$ polymorphisms, fat mass, and anthropometric characteristics in predicting childhood obesity at birth: A cross-sectional study according the parental characteristics and newborn's risk for child obesity (the newborns obesity's risk) NOR study. Medicine (Baltimore). 2016 Jul;95 (29):e4265. der. Systemic inflammation associated to child's obesity might be diagnosed through the assessment of CBC parameters or ESR, whose values are higher in obese children. Moreover, the evaluation of lipid profile an liver function might prove the early settlement of negative multisystemic effects associated to obesity. Further studies taking into account also other environmental factors in order to establish the precise role of each of them in childhood obesity determinism.

Conflict of interest: none declared Financial support: none declared

15. Mărginean CO, Mărginean C, Bănescu C, Meliţ LE, Tripon F, lancu M. The relationship between MMP9 and ADRA2A gene polymorphisms and mothers-newborns' nutritional status: an exploratory path model (STROBE compliant article). Pediatr Res. 2019 Feb 21;

16. Mărginean $C$, Mărginean CO, Bănescu $C$, Meliţ L, Tripon F, lancu M. Impact of demographic, genetic, and bioimpedance factors on gestational weight gain and birth weight in a Romanian population: A cross-sectional study in mothers and their newborns: The Monebo study (STROBE-compliant article). Medicine (Baltimore). 2016 Jul;95 (27):e4098.

17. Mărginean CO, Mărginean C, Voidăzan S, Meliţ L, Crauciuc A, Duicu $C$ et al. Correlations Between Leptin Gene Polymorphisms 223 A/G, 1019 G/A, 492 G/C, 976 C/A, and Anthropometrical and Biochemical Parameters in Children With Obesity: A Prospective Case-Control Study in a Romanian Population-The Nutrichild Study. Medicine (Baltimore). 2016 Mar;95 (12):e3115.

18. Furuncuoğlu Y, Tulgar S, Dogan AN, Cakar S, Tulgar YK, Cakiroglu B. How obesity affects the neutrophil/lymphocyte and platelet/lymphocyte ratio, systemic immune-inflammatory index and platelet indices: A retrospective study. Eur Rev Med Pharmacol Sci. 2016 Apr;20 (7):1300-6.

19. Bozkuş F, Dikmen N, Samur A, Bilal N, Atilla N, Arpağ H. Does the neutrophil-to-lymphocyte ratio have any importance between subjects with obstructive sleep apnea syndrome with obesity and without obesity? Tuberk Toraks. 2018 Mar;66 (1):8-15.

20. Atmaca H, Akbaș F, Ökten I, Nuhoğlu E, Belçik İnal B. Can Neutrophilto-Lymphocyte Ratio Serve as an Inflammatory Marker in Obesity? İstanbul Med J. 2014;15:216-20.

21. Keskin Kurt R, Okyay AG, Hakverdi AU, Gungoren A, Dolapcioglu KS, Karateke $A$, et al. The effect of obesity on inflammatory markers in patients with PCOS: a BMI-matched case-control study. Arch Gynecol Obstet. 2014 Aug;290 (2):315-9.

22. Celikbilek M, Dogan S, Ozbakır O, Zararsız G, Kücük H, Gürsoy S, et al. Neutrophil-lymphocyte ratio as a predictor of disease severity in ulcerative colitis. J Clin Lab Anal. 2013 Jan;27 (1):72-6.

23. Balta $S$, Ozturk $C$. The platelet-lymphocyte ratio: A simple, inexpensive and rapid prognostic marker for cardiovascular events. Platelets. 2015;26 (7):680-1.

24. Baker JL, Olsen LW, Sørensen TIA. Childhood body-mass index and the risk of coronary heart disease in adulthood. N Engl J Med. 2007 Dec 6;357 (23):2329-37.

25. Shah PK. High-density lipoprotein mimetics: Focus on synthetic high-density lipoprotein. Am J Cardiol. 2007 Dec 3;100 (11 A):S62-67.

26. Sumner AE. Ethnic differences in triglyceride levels and high-density lipoprotein lead to underdiagnosis of the metabolic syndrome in black children and adults. J Pediatr. 2009 Sep;155 (3):S7.e7-11.

27. Schwimmer JB, Deutsch R, Kahen T, Lavine JE, Stanley C, Behling C. Prevalence of fatty liver in children and adolescents. Pediatrics. 2006 Oct;118 (4):1388-93.

28. Feldstein AE, Patton-Ku D, Boutelle KN. Obesity, nutrition, and liver disease in children. Clin Liver Dis. 2014 Feb;18 (1):219-31. 